\title{
ZERVAMICINS* I AND II, POLYPEPTIDE ANTIBIOTICS PRODUCED BY EMERICELLOPSIS SALMOSYNNEMATA
}

\author{
A. D. Argoudelis, A. Dietz and L. E. Johnson \\ Research Laboratories, The Upjohn Company \\ Kalamazoo, Michigan 49001 U.S. A. \\ (Received for publication February 23, 1974)
}

\begin{abstract}
Zervamicins I and II are new polypeptide antibiotics produced by Emericellopsis salmosynnemata. Zervamicin I is an acidic compound while zervamicin II is a neutral polypeptide like emerimicins, antiamoebin and stilbellin to which both zervamicins are related.
\end{abstract}

In a recent communication ${ }^{1)}$ we reported the production of emerimicins II, III, IV by Emericellopsis microspora grown in a medium supplemented with trans-4- $n$-propyl-L-proline. Extending our studies with other Emericellopsis species we found that Emericellopsis salmosynnemata strain 336 produces several antibacterial agents without addition of trans-4-n-propyl-Lproline to the medium. Two of these compounds have been isolated crystalline and characterized. The production, isolation and characterization of these antibiotics, named zervamicins I and $\mathrm{II}^{* *}$, are the subject of the present communication.

\section{Experimental}

Assay and Testing Procedures

Antibiotic production and purification was measured by a microbiological disc-plate assay procedure $^{2)}$ with Sarcina lutea as the assay organism. Antibacterial activities were also determined by broth dilution methods described by Lewis et $a l^{3}$.

The growth inhibition of the protozoa (Crithidia fasciculata, Tetrahymena pyriformis, and Ochromonas danica) was determined by 2 -fold dilution end points in a medium consisting of glucose, $10 \mathrm{~g} /$ liter; Bacto proteose peptone No. 3, $10 \mathrm{~g} /$ liter (Difco Laboratories, Inc., Detroit, Michigan, U.S. A.); and Yeastolate, $1 \mathrm{~g} /$ liter (Difco Laboratories, Inc.). The protozoa were grown at $26^{\circ} \mathrm{C}$ for 48 hours.

\section{Thin-Layer Chromatographic Procedures}

Thin-layer chromatograms were run on silica gel $G$ using chloroform-methanol $(6: 1 \mathrm{v} / \mathrm{v})$ as the solvent system The antibiotics present in the fermentation or in preparations obtained during purification were detected by bioautography on $S$. lutea-seeded agar trays.

\section{Spectroscopic Methods}

Nuclear magnetic resonance spectra were obtained with a Varian A-60 spectrometer on solutions ( $c a 0.4 \mathrm{ml}, c a 0.25 \mathrm{M}$ ) of the compounds in $\mathrm{d}_{6}$-dimethylsulfoxide. Infrared spectra werd obtained in mineral oil suspension.

Fermentation Procedures

Seed cultures of E. salmosynnemata were prepared in a medium consisting of glucose monohydrate, $10 \mathrm{~g} /$ liter; Bacto peptone, $10 \mathrm{~g} /$ liter (Difco Laboratories, Inc.); and Bacto yeast extract, $2.5 \mathrm{~g} /$ liter (Difco Laboratories, Inc.). The cultures were incubated at $28^{\circ} \mathrm{C}$ for 96 hours

* This paper is dedicated to Professor LeONIDAs ZeRvas, former teacher of the senior author, as a tribute to his pioneering work in the chemistry of polypeptides.

** The antibiotics are also known as zervacins I and II. 
on a rotary shaker. Fermentation medium consisting of glucose monohydrate, $45 \mathrm{~g}$ /liter; Buffalo starch, $40 \mathrm{~g} /$ liter (CPC International, Englewood Cliffs, New Jersey, U. S. A.); Black strap molasses, $20 \mathrm{~g} /$ liter (Knappen Molasses Company, Chicago, Illinois, U.S. A.); Wilson's s.p., granular peptone, $25 \mathrm{~g} /$ liter (Wilson Protein Technology, Division of Wilson Pharm. and Chem. Co., Calumet City, Illinois, U.S. A.); calcium carbonate, $8 \mathrm{~g} /$ liter; and potassium sulfate, $2 \mathrm{~g} /$ liter was adjusted to $\mathrm{pH} 7.2$ and inoculated at a rate of 5 per cent $(\mathrm{v} / \mathrm{v})$ with the 96 -hour seed culture. Fermentations were incubated at $28^{\circ} \mathrm{C}$ on a rotary shaker, and analyzed for antibiotic production by tlc and bioactivity determinations. Beers were harvested after fermentation time of 192 hours.

Isolation of Zervamicins I and II

Filtration. Extraction of the Antibiotics: Fermentation broth ( $c a 6$ liters) was filtered with the aid of diatomaceous earth. The filter cake was washed with one liter of water and the aqueous wash was combined with the clear filtrate.

The filter cake was triturated with 3 liters of absolute methanol, the methanolic extract was concentrated to dryness, and the dry residue was triturated with $500 \mathrm{ml}$ of methanol. Insoluble material was separated by filtration, found bioinactive, and was discarded. The methanolic extract, concentrated to dryness in vacuo, yielded $42 \mathrm{~g}$ of material (prep. A) containing both zervamicins.

The clear filtrate-aqueous wash was extracted three times with 1.2 liter portions of 1 butanol. The butanolic extracts were combined and concentrated to dryness. The obtained residue, $35 \mathrm{~g}$ (prep. B), contained zervamicins I and II, which were separated as described below.

Separation of Zervamicins I and II:

(1) Silica gel chromatography of preparation B (Butanolic extract of clear beer): A column was prepared from $1.8 \mathrm{~kg}$ of silica gel (Merck-Darmstadt Art 7034) packed in chloroformmethanol $(6: 1, \mathrm{v} / \mathrm{v})$. Preparation B was dissolved in $250 \mathrm{ml}$ of the solvent system and this solution was mixed with $150 \mathrm{~g}$ of silica gel. The mixture was concentrated to dryness, the obtained powder was added to the column and the column was eluted with the solvent system. Fractions were collected and analyzed for bioactivity against $S$. lutea and for antibiotic composition by tlc. Zervamicin II $(3.28 \mathrm{~g})$ was eluted first, followed by a mixture of zervamicins $(2.60 \mathrm{~g})$ and zervamicin I $(3.30 \mathrm{~g})$. The antibiotics were isolated as colorless amorphous materials by concentration to dryness of appropriate fractions.

(2) Silica gel chromatography of preparation A (Methanolic extract of the cake): The procedure used was in general identical to that described above. Zervamicin II, $5.0 \mathrm{~g}$, a mixture of zervamicins, $2.81 \mathrm{~g}$ and zervamicin I, $4.0 \mathrm{~g}$ were isolated from chromatography of $42.0 \mathrm{~g}$ of preparation A.

Crystallization of Zervamicins:

(1) Crystallization of zervamicin I: Amorphous zervamicin I, $2.3 \mathrm{~g}$, was dissolved in $9 \mathrm{mI}$ of absolute methanol and $9 \mathrm{ml}$ of acetone. The solution was clarified by filtration. The resulting clear solution was mixed with $225 \mathrm{ml}$ of acetone. Zervamicin I, crystallized in colorless needles, was isolated by filtration and dried; yield $1.32 \mathrm{~g}$.

(2) Crystallization of zervamicin II: Three grams of amorphous zervamicin II was dissolved in $30 \mathrm{ml}$ of hot methanol. This solution was mixed with $80 \mathrm{ml}$ of water. Zervamicin II, crystallized in colorless needles, was isolated by filtration and dried; yield $1.92 \mathrm{~g}$. Recrystallization of this material from $30 \mathrm{ml}$ of hot methanol and $80 \mathrm{ml}$ of water yielded $1.6 \mathrm{~g}$ of crystalline zervamicin II. Characterization of both zervamicins is described in the next section of this communication.

\section{Discussion and Results}

Production of Zervamicins I and II by Strains of Emericellopsis salmosynnemata

Emericellopsis salmosynnemata strain 336 produces several antibiotics inhibiting the test 
organism (S. lutea) used in the present studies. The time sequence of production of zervamicins was followed by tlc. A thin-layer chromatographic comparison of the two antibiotics is presented in Fig. 1. Zervamicin II can be detected after 144 hours of fermentation, while zervamicin I is present after 168 hours. Production of both zervamicins reaches a maximum after 192 hours. An antibiotic inactivated by $\beta$-lactamase is produced early ( $48 \sim 72$ hours) in the fermentation. However, this antibiotic is not present in culture filtrates analyzed after 144 hours of fermentation when production of zervamicins is taking place.

E. salmosynnemata strain 336 was derived from E. salmosynnemata IMI 58330.* Strain IMI 58330 was derived from Cephalosporium

Fig. 1. Thin-layer chromatographic comparison of zervamicins I and II

Solvent: Chloroform-methanol $(6: 1, \mathrm{v} / \mathrm{v})$

Support: Eastman's chromagram 6061 silica gel sheets. Antibiotics were detected by bioautography on Sarcina lutea-seeded agar trays

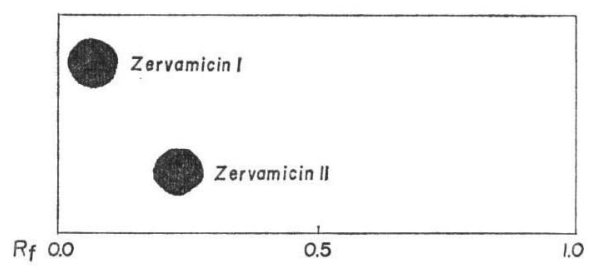
salmosynnematum** MDH 3590 A, NRRL 2271

which has been reported to produce synnematin (penicillin $\mathrm{N})^{4)}$. These strains as well as $E$. salmosynnemata ATCC 11661 were tested for production of zervamicins under identical fermentation conditions. Of these cultures only E. salmosynnemata strains 336 and IMI 58330 produce zervamicins while all cultures produced the $\beta$-lactamase sensitive antibiotic.

\section{Characterization of Zervamicins I and II}

Zervamicins I and II have been isolated as colorless crystalline materials (needles). The antibiotics are soluble in dimethylformamide, dimethylsulfoxide and lower alcohols. They are less soluble in chlorinated hydrocarbon solvents and ethyl acetate. They are insoluble in acetone, ether and saturated hydrocarbon solvents.

Table 1. Physical properties of zervamicins

\begin{tabular}{|c|c|c|c|c|}
\hline & \multicolumn{2}{|c|}{ Zervamicin I } & \multicolumn{2}{|c|}{ Zervamicin II } \\
\hline$[\alpha]_{\mathrm{D}}^{25}(c)$, methanol $)$ & \multicolumn{2}{|l|}{+16} & \multicolumn{2}{|c|}{$+4.5^{\circ}$} \\
\hline Melting point (unc., dec.) & \multicolumn{2}{|l|}{$220^{\circ}$} & \multicolumn{2}{|c|}{$257^{\circ}$} \\
\hline $\begin{array}{l}\text { UV (Methanol) } \\
\lambda_{\max }, \operatorname{nm}(\mathrm{a})\end{array}$ & $\begin{array}{l}217 \text { (sh) } \\
264 \text { (sl. sh) } \\
268 \text { (sl. sh) } \\
273 \\
282 \\
289 \\
315\end{array}$ & $\begin{array}{c}(22.47) \\
- \\
- \\
(2.82) \\
(3.04) \\
(2.74) \\
(0.41)\end{array}$ & $\begin{array}{l}216 \text { (sh) } \\
264 \text { (sl. sh) } \\
268 \text { (sh) } \\
274 \\
281 \\
289\end{array}$ & $\begin{array}{r}(23.10) \\
(2.22) \\
(2.46) \\
(2.67) \\
(2.86) \\
(2.52)\end{array}$ \\
\hline Potentiometric titration* & $\begin{array}{l}\text { Acidic, } \mathrm{pKa}^{\prime} 5.5, \\
1,513\end{array}$ & uiv. weight, & Neutral & \\
\hline IR (Nujol) $\left(\mathrm{cm}^{-1}\right)$ & $\begin{array}{l}3400,3300,3060, \\
1415,1380\end{array}$ & 645,1540 & $\begin{array}{l}3400,3300,30 \\
1535,1410,13\end{array}$ & (sh), 1647, \\
\hline
\end{tabular}

* The antibiotics were titrated in $72 \%$ aqueous ethanol with either sodium hydroxide or hydrochloric acid.

* Obtained from the Commonwealth Mycological Institute.

** Cephalosporium salmosynnematum is also known as Emericellopsis salmosynnemata. 
Physical properties of zervamicins I and II are presented in Table 1. The antibiotics are dextrorotatory, melt at tempetatures over $200^{\circ} \mathrm{C}$ (with decomposition) and have identical UV spectra. Potentiometric titration in $72 \%$ aqueous ethanol, using sodium hydroxide or hydrochloric acid as titrants, showed the presence of an acidic group in zervamicin I, $\mathrm{pKa}^{\prime}$ 5.5; equivalent weight, 1513. Zervamicin II, on the other hand, behaves like a neutral material. The infrared spectra (in Nujol mull) of zervamicins I and II are very similar so that it is impossible to differentiate these two compounds using IR data. Both compounds show absorption at $3400 \sim 3300 \mathrm{~cm}^{-1}$ due to $-\mathrm{NH}$ or $-\mathrm{OH}$ stretching vibrations. The most characteristic absorption in the spectra is that due to the stretching vibration of amide carbonyl which appears at $\mathrm{ca} 1645 \mathrm{~cm}^{-1}$ (amide I). Amide II carbonyl absorptions appear as $1535 \sim 1540 \mathrm{~cm}^{-1}$. The IR spectra of zervamicins suggested polypeptide type of antibiotics. This was confirmed by determination of the amino acid content of these antibiotics (Table 2). Small amounts of serine, glycine, alanine and valine corresponding to less than 0.20 mole per mole of leucine were found in zervamicin I. Similarly small amounts of lysine and valine were found in zervamicin II. We believe that these amino acids are not present in the respective antibiotics and the results are artifacts.

Analytical data (Table 3) obtained on zervamicins I and II suggest the relative elemental compositions shown in Table 3. The molecular formula of zervamicin $\mathbf{I}$, an acidic polypeptide, is indicated to be $\mathrm{C}_{70} \mathrm{H}_{114} \mathrm{~N}_{14} \mathrm{O}_{21}$

Table 2. Relative amino acid content of antibiotics

\begin{tabular}{l|c|c}
\hline \multicolumn{1}{c|}{ Aminoacid } & Zervamicin I & Zervamicin II \\
\cline { 1 - 2 } Lysine & 1 & - \\
Hydroxyproline & 2 & 2 \\
Threonine & 1 & 1 \\
Glutamic acid & 2 & 2 \\
Proline & 1 & 1 \\
$\alpha$-Aminoisobutyric & 1 & 1 \\
acid & 2 & 2 \\
Isoleucine & 1 & 1 \\
Leucine & & \\
\hline
\end{tabular}

Fig. 2. Infrared spectra of zervamicins (in Nujol mull)

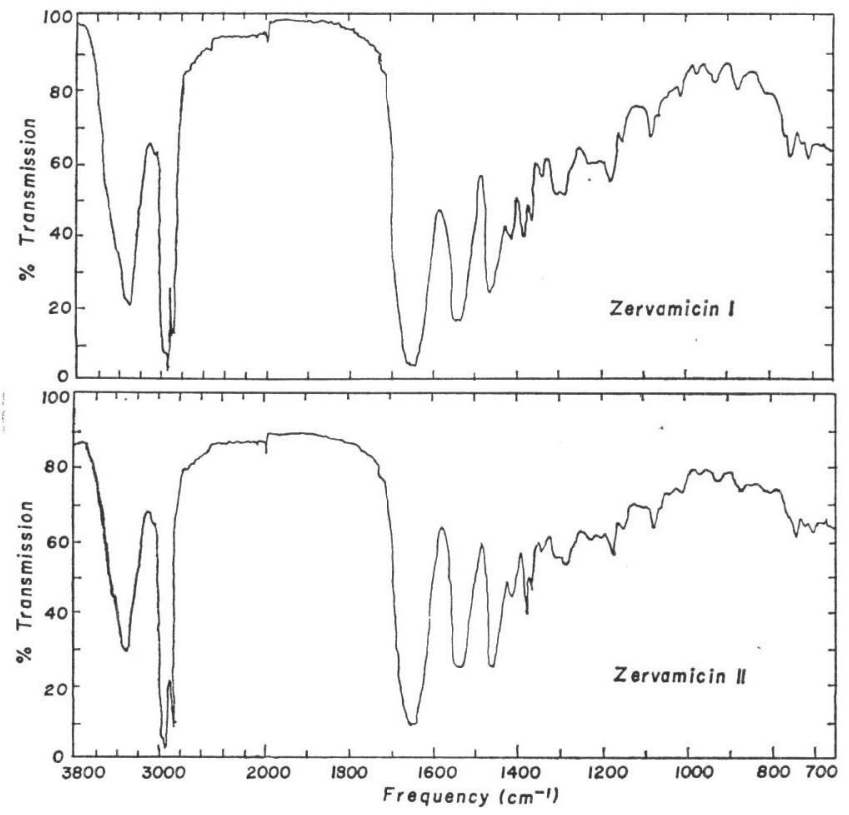


(calcd. mol. weight, 1,486) assuming that the equivalent weight is equal to the molecular weight. The amino acid composition results show that zervamicin II, a neutral polypeptide, is also a high molecular weight compound. Conventional techniques (osmometric methods, mass spectrometry) were not helpful in determining the molecular weight of this antibiotic. However, some approximation of the molecular size of zervamicin II could be made based on the amino acid content results. Zervamicin II would have a minimum molecular weight of 1,126 if the amino acids listed in Table 2 were the only moieties present in the antibiotic.

Table 3. Analytical data and molecular formulas of zervamicins

\begin{tabular}{c|c|c|c}
\hline & & Zervamicin I & Zervamicin II \\
\hline \multirow{2}{*}{ Anal. Data } & $\mathrm{C}$ & 56.49 & 56.01 \\
& $\mathrm{H}$ & 7.50 & 7.60 \\
& $\mathrm{~N}$ & 13.26 & 13.34 \\
& $\mathrm{O}$ (diff.) & 22.75 & 23.05 \\
& $\mathrm{~S}$ & 0 & 0 \\
& Halogen & 0 & 0 \\
\hline Calcd elem. composition & $\left(\mathrm{C}_{4.70} \mathrm{H}_{7.50} \mathrm{~N}_{0.84} \mathrm{O}_{1.42}\right)_{\mathrm{n}}$ & $\left(\mathrm{C}_{4.66} \mathrm{H}_{7.80} \mathrm{~N}_{0.85} \mathrm{O}_{1.44}\right)_{\mathbf{n}}$ \\
Estimated mol. weight* & 1,486 & 1,998 \\
Suggested mol. formula* & $\mathrm{C}_{70} \mathrm{H}_{114} \mathrm{~N}_{14} \mathrm{O}_{21}$ & $\mathrm{C}_{93} \mathrm{H}_{152} \mathrm{~N}_{19} \mathrm{O}_{28}$ \\
\hline
\end{tabular}

* For discussion related to the estimation of the molecular weights and molecular formulas see text.

However, we have determined that the amino acids present in the antibiotic. However, we have determined that the amino acids present in zervamicin II contribute to $57 \%$ of the weight of the antibiotic. We concluded, therefore, that the minimum molecular weight of zervamicin II is $c a 1,975$. On the basis of these assumptions we suggest the molecular formula of $\mathrm{C}_{93} \mathrm{H}_{152} \mathrm{~N}_{19} \mathrm{O}_{29}$ as an approximate molecular formula for zervamicin II.

The proton magnetic resonance spectra of zervamicins I and II (Fig. 3) offer little help in determining the nature of the antibiotics. The spectra are presented in this paper as an additional aid for the differentiation of zervamicins from other antibiotics.

\section{Relation of Zervamicins to Other Antibiotics*}

Zervamicins I and II are easily differentiated (IR spectra) from the $\beta$-lactam antibiotics penicillin $\mathrm{N}$, cephalosporin $\mathrm{C}^{5)}$ and emericellopsin $\mathrm{A}^{8)}$ produced by different Emericellopsis species. Zervamicins are also different from another class of compounds, the cephalosporin $\mathbf{P}$ antibiotics, which are steroid-like materials and are also produced by Emericellopsis species ${ }^{7)}$.

Other antibiotics reported to be produced by Emericellopsis species are the neutral polypeptides antiamoebin ${ }^{8,9)}$ and emerimicins II, III and IV $^{1)}$ which have properties similar to those of zervamicins. Zervamicin I, being an acidic polypeptide, can be easily differentiated from these antibiotics. Furthermore zervamicin I has been separated from antiamoebin and the emerimicins by tlc on silica gel using chloroform-methanol $(6: 1, \mathrm{v} / \mathrm{v})$ or ethyl acetate - acetone water $(8: 5: 1, \mathrm{v} / \mathrm{v})$. Zervamicin II, a neutral polypeptide, is easily differentiated from antiamoebin and emerimicins III and IV by tlc and by comparison of their respective amino acid

\footnotetext{
* For discussion on the antibiotics produced by Emericellopsis species see Ref. 1 .
} 
Fig. 3. Proton magnetic resonance spectra of zervamicins I and II (in $\mathrm{d}_{6}$-DMSO)

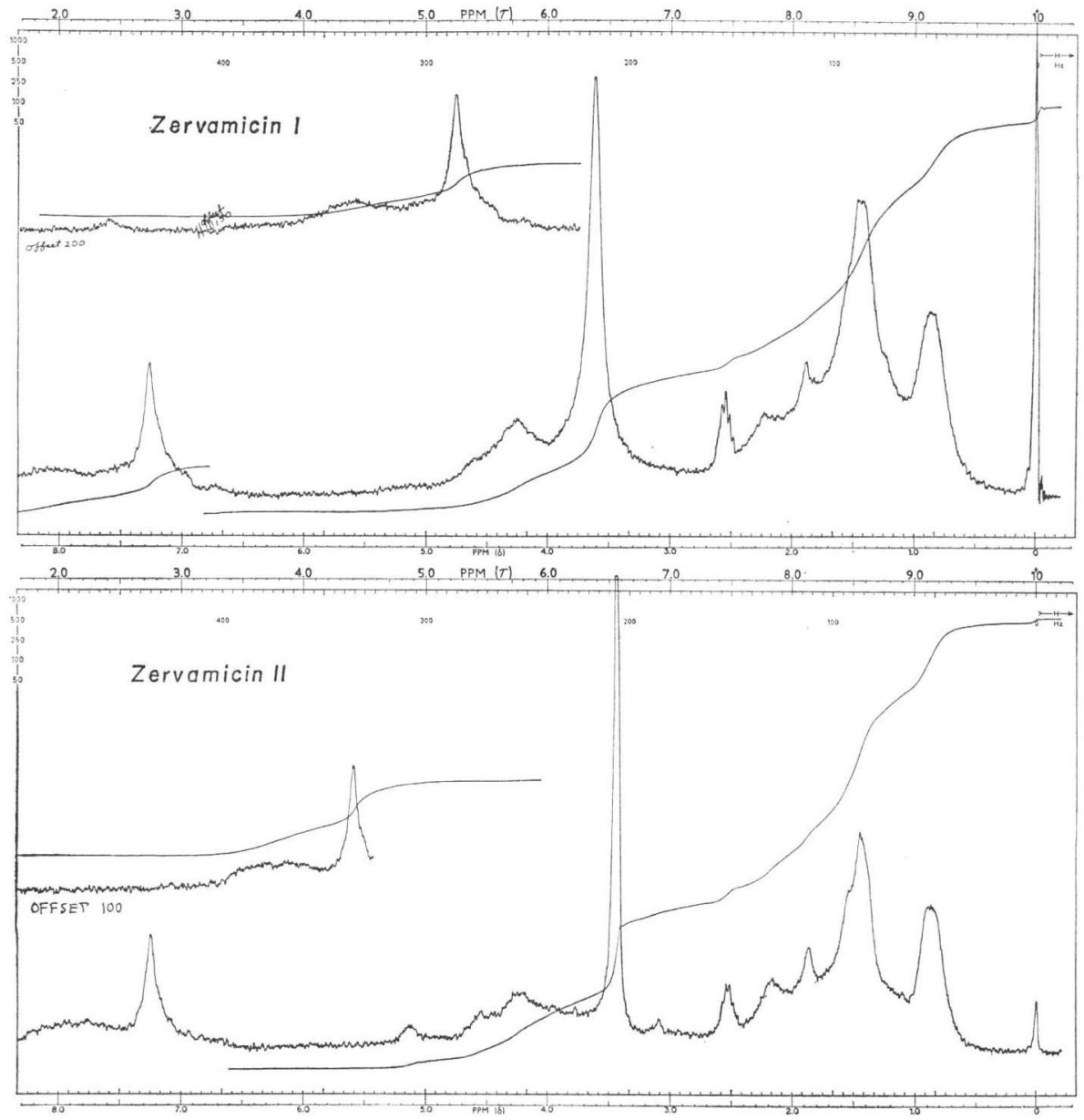

Table 4. Antibacterial spectra of zervamicins* I and II

\begin{tabular}{l|c|c}
\hline \multicolumn{1}{c}{ Test organism } & \multicolumn{2}{|c}{ Minimum inhibitory concentration (mcg/ml) } \\
\cline { 2 - 3 } & Zervamicin I & Zervamicin II \\
\hline Staphylococcus aureus UC 76 & 500 & 8 \\
Staphylococcus aureus UC 552 & 500 & 16 \\
Streptococcus hemolyticus UC 152 & 16 & 4 \\
Streptococcus faecalis UC 3235 & 62 & 8 \\
Escherichia coli UC 51 & 500 & 250 \\
Proteus vulgaris UC 93 & 500 & 500 \\
Klebsiella pneumoniae UC 57 & 500 & 250 \\
Salmonella schottmuelleri UC 126 & 500 & 250 \\
Pseudomonas aeruginosa UC 95 & 250 & 125 \\
Bacillus subtilis UC 564 & 500 & 8 \\
Diplococcus pneumoniae UC 41 & 16 & 2 \\
Sarcina lutea UC 130 & 250 & 4 \\
\hline
\end{tabular}

* Test method: Two-fold dilution endopoints in brain heart infusion broth; incubate at $37^{\circ} \mathrm{C}$ for 20 hours. 
composition. Specifically zervamicin II contains (Table 2) threonine and isoleucine which are not present in antiamoebin or emerimicins III and IV. Zervamicin II has tlc behavior, IR and UV spectra and biological properties similar to those of emerimicin II. The two antibiotics differ in the presence of lysine* in emerimicin II and in slight difference in their proton magnetic resonance spectra. Specifically, an absorption peak at $\delta 1.28$, present in the spectrum of emerimicin II is not present in the spectrum of zervamicin II. We therefore propose that the two closely related antibiotics are different.

Another antibiotic resembling the zervamicins is stilbellin $^{10)}$ produced by the fungus Stilbella sp. This neutral polypeptide antibiotic has been differentiated from the zervamicins by tlc (systems same as above) and by comparison of the amino acid composition of the antibiotics respectively.

\section{Biological Properties of Zervamicins I and II}

The in vitro antibacterial spectra of zervamicins are presented in Table 4 . Zervamicin II is more active than zervamicin I against all organisms tested. Both antibiotics are active mainly against Gram-positive organisms. Zervamicins I and II do not possess significant in vitro antifungal activity, but showed in vitro activity against selected protozoa. Zervamicin II is active against Crithidia fasciculata at $50 \mathrm{mcg} / \mathrm{ml}$, Tetrahymena pyriformis at $25 \mathrm{mcg} / \mathrm{ml}$ and Ochromonas danica at $200 \mathrm{mcg} / \mathrm{ml}$, while zervamicin I showed no activity at $200 \mathrm{mcg} / \mathrm{ml}$ versus C. fasciculata and $O$. danica, but was active at $100 \mathrm{mcg} / \mathrm{ml}$ against $T$. pyriformis. In vivo evaluation of zervamicins I and II is in process.

\section{Acknowledgement}

The authors express their appreciation to Mr.K.J. Geipel and Mrs. M. Little for technical assistance, to members of the Physical and Analytical Chemistry Department of The Upjohn Company for analytical and spectra data and to the Fermentation Research and Development Unit of The Upjohn Company for large scale production of the antibiotics.

\section{References}

1) Argoudelis, A. D. \& L.E. Johnson: Emerimicins II, III and IV, antibiotics produced by Emericellopsis microspora in media supplemented with trans-4-n-propyl-L-proline. J. Antibiotics $27: 274 \sim$ 282, 1974

2) Hanka, L. J.; M. R. Burch \& W. T. Sokolski: Psicofuranine. IV. Microbiological assay. Antibiot. \& Chemoth. 9: 432 435, 1959

3) Lewis, C.; W. Clapp \& J.E. GRady: In vitro and in vivo evaluation of lincomycin, a new antibiotic. Antimicr. Agents \& Chemoth. -1962: 570 582, 1963

4) Gottshal, R. Y.; T. M. Roberts \& L. M. Portwood: Synnematin and process of producing the same. U.S. Patent 2,658,018, 1953

5) Lemke, P. A. \& D. R. Brannon: Microbial synthesis of cephalosporin and penicillins, chemistry and biology. E. H. Flynn Ed. p. 371, Academic Press. 1972

6) Cole, M. \& G. M. Rolinson: 6-Aminopenicillanic acid. II. Formation of 6-aminopenicillanic acid by Emericellopsis minima (Stolk) and related fungi. Proc. Roy. Soc. B 154: 490 497, 1961

7) Kavanagh, F.; D. Tunin \& G. Wild: Antibiotics formed by species of Emericellopsis. Mycologia 50: $370 \sim 372,1958$

8) Thirumalachar, M. J.: Antiamoebin, a new antiprotozoal-anthelmintic antibiotic. I. Production and biological studies. Hindustan Antibiot. Bull. 10: 287 289, 1968

* It should be noted, however, that amino acid determination of zervamicin II showed the presence of some lysine ( 0.25 mole per mole of leucine). 
9) Deshmukh, P. V.: Antiamoebin, a new antiprotozoal-anthelmintic antibiotic. II. Chemical characterization. Hindustan Antibiot. Bull. 10: 299 302, 1968

10) Sasaki, K.; H. Minato, K. Katagiri, S. Hayakawa \& T. Matsushima: Stilbellin, a new antibiotic from Stilbella sp. J. Antibiotics 24: 67 68, 1971 